\title{
Karakterisasi Metode Panas-Dingin Zat Warna Alam Bakau Dan Konsentrasi Merang Dengan Variasi Perlakuan Fiksator Pada Aplikasi Kain
}

\author{
Azafilmi Hakiim ${ }^{1,{ }^{*}}$, Dessy Agustina Sari ${ }^{2)}$ dan Cintiya Septa Hasannah ${ }^{3)}$ \\ ${ }^{1,2,3}$ Fakultas Teknik Program Studi Teknik Kimia Universitas Singaperbangsa Karawang \\ *) Corresponding author: aza252116@gmail.com \\ ((Received 28-Oct-19・Revised 25-Nov-19・Accepted 29-Nov-2019)
}

\begin{abstract}
Mangrove is a potential source of local coastal Karawang Regency, which is processed into color powder in the implementation of textile fabrics. This research presented a renewed study of the processing of natural dyes (ZWA) from powders with cold heat treatment with variations in the composition of the straw and tested on the influence of the type of fixator on variations in fabric types (plain cotton cloth, plain silk, and batik cotton). The hot and cold method is done by immersing mangrove powder with a composition of $100 \mathrm{gr} / \mathrm{lliter}$ of water, added to the variable composition of the burned straw (hot method) 100gr / 1liter and 200gr / liter of water for 48 hours. The results of natural dyes (ZWA) produced from the hot and cold method are then tested on variations in fabric type, with non-fixator treatment (as a comparison and appearance of color originality) and fixation variations (alum, lime, and tunjung). The parameters of the test results are carried out on a qualitative rating scale based on the staining scale in the washing test, the fading test, and the blazing sun. The qualitative data processing uses two-way ANOVA with a real difference at the $5 \%$ test level. The results showed that in the two-way ANOVA processing produced a significant difference between the different treatments of composition $A$ and $B$ of the various perceptions of the existence of fixators. Based on this, the best conditions were obtained for the treatment of composition A. While the effect of various types of assessment on the type of fabric, no significant difference was found.
\end{abstract}

\begin{abstract}
Abstrak
Bakau merupakan sumber potensi lokal pesisir Kabupaten Karawang, yang diolah menjadi serbuk warna pada implementasi kain tekstil. Pada penelitian ini menyajikan kajian terbaharukan dari pengolahan zat warna alam (ZWA) dari serbuk dengan perlakuan panas dingin dengan variasi komposisi merang dan diuji terhadap pengaruh jenis fiksator terhadap variasi jenis kain (kain katun polos, sutera polos dan katun batik). Metode panas dingin dilakukan dengan merendam serbuk bakau dengan komposisi 100gr/1liter air, ditambahkan dengan variabel komposisi merang yang dibakar (metode panas) 100gr/1liter dan $200 \mathrm{gr} / 1$ liter air selama $48 \mathrm{jam}$. Zat warna alam yang dihasilkan, kemudian diujikan ke variasi jenis kain, dengan perlakuan non fiksator (sebagai pembanding dan kenampakan originalitas warna) dan variasi fiksator (tawas, kapur, dan tunjung). Parameter hasil uji dilakukan terhadapa skala penilaian kualitatif berdasarkan staining scale pada uji pencucian, uji kelunturan dan terik matahari. Pengolahan data kualitatif tersebut menggunakan ANOVA dua arah dengan beda nyata pada taraf uji 5\%. Hasil penelitian menunjukkan, pada pengolahan ANOVA dua arah dihasilkan perbedaan yang signifikan antara beda perlakuan komposisi A dan B terhadap ragam penilaian persepsi keberadaan fiksator. Berdasarkan hal tersebut diperoleh kondisi terbaik pada perlakuan komposisi A. Sedangkan pengaruh ragam penilaian terhadap jenis kain, tidak ditemukan perbedaan yang nyata.
\end{abstract}

Keywords: cloth, fixator, mangrove, ZWA 


\section{PENDAHULUAN}

Kabupaten Karawang merupakan wilayah dengan kondisi sumber daya pesisir berupa perikanan tangkap dan ekosistem (hutan bakau) sepanjang panjang pantai 76,42 km dan luas pesisir lebih $2 / 3$ dariluas wilayah seluruhnya atau sekitar $1.168,85 \mathrm{~km}$ atau $3,73 \%$ dari luas provinsi Jawa Barat. Keberadaan hutan mangrove dari jenis tanaman bakau di kawasan pesisir merupakan ekosistem flora maupun fauna dan digunakan sebagai pencegah terjadinya abrasi di pesisir pantai. Beberapa jenis tanaman bakau diantaranya Rhizophora mucronata, Rhizophora apiculata, Sonneratia alba, Avecennia marina, Acanthus ilicifolius, Nypa fruticans, dan Derris trifoliata. Dari beberapa jenis tanaman bakau tersebut, keberadaan paling banyak di hutan mangrove adalah jenis Rhizophora spp. Jenis Rhizophora spp (Rhizophora mucronata dan Rhizophora apiculata) yang sudah berumur empat tahun akan menghasilkan buah bakau yang digunakan untuk pembuatan bibit dalam pengembangan tanaman mangrove [1].

Bibit bakau yang digunakan yaitu buah mangrove yang sudah berkecambah atau propagul. Pembibitan masal yang dilakukan dalam setahun sebanyak dua sampai tiga kali dengan jumlah 20.000 hingga 50.000 benih pada setiap pembibitan. Pada setiap pembibitan yang dilakukan akan menghasilkan 10\% hingga $20 \%$ propagul kering atau mati dari semua bibit bakau. Namun, jika curah hujan terlalu tinggi atau bibit propagul terlalu lama tidak ditanam dari proses pemetikan, dapat mengakibatkan stress yang akhirnya membuat bibit propagul tersebut kering atau mati. Biasanya jika terjadi hal hal demikian propagul yang kering dapat mencapai $30 \%$. Propagul yang telah kering tersebut memiliki kandungan pigmen yang dapat berpotensi digunakan sebagai pewarna alam. Pewarna alam dari propagul kering masih jarang digunakan atau belum berkembang sehingga masih belum dikenal oleh masyarakat umum [1].

Masalah utamanya dari beberapa hasil dari pengolahan propagul tanaman bakau jenis Rhizophora mucronata masih dibatasi pada lemahnya pada kualitas warna terhadap ketahanan luntur warna yang dihasilkan. Ada beberapa faktor yang mempengaruhi di dalamnya, salah satunya proses pengolahan bahan baku yang hanya pada sampai ${ }^{1)}$ proses perebusan (perlakuan panas) yang kemudian disaring dan diambil cairannya; ${ }^{2)}$ minimnya penambahan pelarut berbahan dasar alam; ${ }^{3)}$ dan minimnya teknik pencelupan untuk memperkuat daya rekat pada kain batik.

Beberapa peneiti yang sudah mengembangkannya diantaranya: ${ }^{1)}$ cara ekstraksi dengan rasio perebusan 1:10 menggunakan fiksasitawas, kapur, dan tunjung, dari perlakuan tersebut gabungan fiksasi kapur dan tunjung menghasilkan karakterisasi corak warna yang lebih kuat dan tidak luntur [2]; ${ }^{2}$ metode microwave assisted extraction dengan konsentrasi pelarut etanol $20 \%, 40 \%, 60 \%, 80 \%, 96 \%$, dihasilkan semakin besar rasio bahan dengan pelarut maka \% yield yang diperoleh semakin menurun, dan \% yield tertinggi sebesar 53,0529\% dicapai pada kondisi rasio $1: 15(\mathrm{~g} / \mathrm{ml})$ untuk pelarut etanol 96\% $[3] ;{ }^{3)}$ cara ekstraksi dengan variasi pelarut etanol 95\%, 70\% dan air,dihasilkan pelarut paling baik etanol 95\% dihasilkan pada uji kain pewarnaan grey scale (GS) dan staining scale (SS) dengan yield 21,430\% [4]; ${ }^{4)}$ metode teknik celup rintang pada proses ekstrak pengolahan propagul menjadi zat warna alam yang divariasikan dalam mordanting yang bersifat asam, basa dan logam. Produk warna pekat dari teknik celup rintang dihasilkan dari proses penambahan variasi mordanting yang bersifat basa (kapur sirih) dan logam (tunjung) [1].

Kajian terbaharukan dari penelitian ini metode panas dingin yang digunakan dari kombinasi campuran serbuk bakau dan merang bakar terhadap pengarus fiksator pada uji pencucian, kelunturan dan terik matahari. 


\section{METODE PENELITIAN}

Tahapan Penelitian terbagi atas ${ }^{1)}$ persiapan bahan baku dan alat; ${ }^{2)}$ penggunaan proses menggunakan metode panas-dingin; ${ }^{3)}$ pengaruh terhadap fiksator; ${ }^{4)}$ pengujian terhadap pencucian, kelunturan dan terik matahari yang dinilai menggunakan kategori nilai staining scale $;{ }^{5)}$ pengolahan data menggunakan Hitung $\mathrm{F}$.

Tahapan persiapan bahan baku terdiri bahan baku utama yaitu bakau yang dibuat serbuk dengan cara memilih bakau siap panen dengan rentan usia 5-10 tahun, dengan mengambil kulitnya, dan dikeringkan selama 3 hari di bawah terik matahari. Kemudian digiling dengan mesin penggiling buatan. Bahan baku lainnya seperti merang ditimbang berdasarkan variasi komposisi yakni a) 100 gr dan ${ }^{\text {b) }} 200$ gr yang dibakar terlebih dahulu, kemudian dimasukkan ke wadah berisi air dingin 1liter, dan dibiarkan mengendap. Ambil cairan filtratnya.

Tahapan proses dilakukan dengan cairan filtrat dari pembakaran merang dicampurkan pada komposisi bakau 100gr/1liter air, aduk merata dan simpan selama 48 jam agar terjadi kontak kedua cairan tersebut. Selanjutnya pengambilan fitrat cairan dan digunakan pada aplikasi pewarna pada kain.

Tahapan fiksator dilakukan dengan menyiapkan kain jenis katun polos, sutera polos, dan katun corak batik pada tahapan proses pewarnaan dengan melakukan teknik pencelupan berulang-ulang pada filtrat cairan warna alam yang dihasilkan dari sebelumnya. Kemudian membandingkan warna originalitas (tanpa fiksasi) yang dihasilkan terhadap penambahan pengaruh pelarut fiksator (tawas, kapur, dan tunjung).

Dari hasil tersebut, kemudian masuk dalam tahapan uji, dilakukan dari uji pencucian dengan menggunakan detergen sebanyak $5 \mathrm{gr} / 1$ liter air dan dilakukan pembilasan hingga buih detergen tidak menempel dikain. Selanjutnya kain dikeringkan di bawah sinar matahari.

Sampel kain yang melalui tahap uji dinilai oleh responden dari praktisi batik yang didasarkan pada penilaian kualitatif staining scale.

Perolehan data yang dihasilkan diolah menggunakan ANOVA dua arah dengan pengaruh faktor yang berbeda nyata pada taraf uji $5 \%$.

\section{HASIL DAN PEMBAHASAN}

Hasil penelitian berdasarkan penilaian kualitatif staining scale yang dinilai pada kisaran scale tinggi (baik sekali) 5, 4-5, 4; sedang (cukup baik) 4-3, 3, 3-2 ditunjukkan pada perolehan Tabel 1; Tabel 2.; Tabel 3; Tabel 4. Penilaian skala ini diberikan oleh responden yang mana merupakan praktisi dibidang batik warna alam sebanyak 3 orang, dengan jumlah dua perlakuan A (100 gr/l pelarut merang bakar) dan B (200 gr/l pelarut merang bakar) yang dibandingkan dengan ragam persepsi penilaian adanya pengaruh peranan fiksator sebagai berikut: 
Tabel 1. Penilaian Uji Pencucian, Kelunturan dan Terik Matahari Pada Implementasi Kain Sutera Terhadap Beda Perlakuan Komposisi A dan Komposisi B

\begin{tabular}{cccccc}
\hline \multirow{2}{*}{ No. } & Perlakuan & $\begin{array}{c}\text { Non } \\
\text { Fiksasi }\end{array}$ & $\begin{array}{c}\text { Fiksasi } \\
\text { Tawas }\end{array}$ & $\begin{array}{c}\text { Fiksasi } \\
\text { Kapur }\end{array}$ & $\begin{array}{c}\text { Fiksasi } \\
\text { Tunjung }\end{array}$ \\
\hline 1. & & 2,5 & 3,5 & 3,5 & 3 \\
2 & A & 2 & 4 & 4 & 3 \\
3 & & 3 & 3 & 4 & 2,5 \\
1 & & 2,5 & 3 & 3 & 3 \\
2 & \multirow{2}{*}{ B } & 2,5 & 2,5 & 3,5 & 3 \\
3 & & 1 & 2 & 2,5 & 3 \\
\hline
\end{tabular}

Tabel 2. Penilaian Uji Pencucian, Kelunturan dan Terik Matahari Pada Implementasi Kain Katun Polos Terhadap Beda Perlakuan Komposisi A dan Komposisi B

\begin{tabular}{cccccc}
\hline \multirow{2}{*}{ No. } & \multirow{2}{*}{ Perlakuan } & $\begin{array}{c}\text { Non } \\
\text { Fiksasi }\end{array}$ & $\begin{array}{c}\text { Fiksasi } \\
\text { Tawas }\end{array}$ & $\begin{array}{c}\text { Fiksasi } \\
\text { Kapur }\end{array}$ & $\begin{array}{c}\text { Fiksasi } \\
\text { Tunjung }\end{array}$ \\
\hline 1. & \multirow{2}{*}{ A } & 2,5 & 3 & 3 & 2,5 \\
2 & 2,5 & 3 & 3,5 & 2,5 \\
3 & & 2 & 3 & 3 & 3 \\
1 & & 2,5 & 2,5 & 3 & 3 \\
2 & \multirow{2}{*}{$\mathrm{B}$} & 2 & 2,5 & 3 & 2,5 \\
3 & & 2 & 2 & 3,5 & 2,5 \\
\hline
\end{tabular}

Tabel 3. Penilaian Uji Pencucian, Kelunturan dan Terik Matahari Pada Implementasi Kain Katun Batik Terhadap Beda Perlakuan Komposisi A dan Komposisi B

\begin{tabular}{cccccc}
\hline \multirow{2}{*}{ No. } & Perlakuan & $\begin{array}{c}\text { Non } \\
\text { Fiksasi }\end{array}$ & $\begin{array}{c}\text { Fiksasi } \\
\text { Tawas }\end{array}$ & $\begin{array}{c}\text { Fiksasi } \\
\text { Kapur }\end{array}$ & $\begin{array}{c}\text { Fiksasi } \\
\text { Tunjung }\end{array}$ \\
\hline 1. & & 3 & 2,5 & 3 & 3 \\
2 & A & 3,5 & 2,5 & 3 & 3 \\
3 & & 2 & 2,5 & 3,5 & 3 \\
1 & & 2,5 & 2,5 & 3 & 3 \\
2 & \multirow{2}{*}{$\mathrm{B}$} & 2,5 & 2,5 & 3,5 & 3 \\
3 & & 3 & 2 & 3 & 3 \\
\hline
\end{tabular}

Tabel 1, Tabel 2 dan Tabel 3 rata-rata menunjukkan bahwa pada perbedaan perlakuan komposisi terbaik rata-rata pada jenis perlakuan A yang dipengaruhi kuat keberadaan fiksator. Fiksator merupakan zat khusus yang dapat meningkatkan lekatnya berbagai pewarna pada kain. Pemberian fiksator dapat memperbesar daya serap kain terhadap zat warna. Perlakuan fiksator jenis tawas, kapur, dan tunjung menunjukkan uji pencucian, kelunturan dan terik matahari pada nilai rata-rata cukup baik.

Responden menilai untuk jenis fiksator kapur menunjukkan hasil pada kategori rata-rata nilai tinggi. Hal ini dikarenakan kapur mampu mengikat kuat molekul warna. Sifat-sifat fisik kapur adalah berbentuk gumpalan yang tidak teratur, memiliki warna putih atau putih keabu- 
abuan, dan kadang-kadang bernoda kekuningan atau kecokelatan yang disebabkan oleh adanya unsur besi. Penggunaan larutan kapur sebagai fiksator merupakan penambahan garam-garam klorida atau oksalat dari basa-basa organik yang dapat meningkatkan afinitas zat warna terhadap selulosa/serat/kain katun[5].

Fiksator tawas menghasilkan rata-rata penilaian responden dikisaran terbanyak pada skala penilaian 2-3. Karakterisasi dari tawas lebih difungsikan pada penguncian warna yang tidak kesemuanya serat mampu terikat maksimum. Hal ini dimungkinkan ada sebagian warna yang terlepas ketika proses penguncian warna ke dalam serat kain. Sehingga dalam uji pencucian, kelunturan, dan pengeringan di bawah terik matahari menghasilkan warna yang pudar $[6,7,10]$.

Disisi lain, pada penilaian fiksator tunjung menghasilkan rata-rata penilaian yang cukup (skala 3) yang memiliki karakterisasi merubah atau mengalihkan kenampakan warna serat kain yang berbeda dengan warna asli serat sebelum diberikan fiksator. Pengubahan warna yang ini lebih condong pada kenampakan warna gelap. Fiksator tunjung memiliki kandungan ion $\mathrm{Fe}^{2+}$ yang dapat membentuk kompleks logam yang berguna untuk memperbaiki ketahanan luntur warna pada kain $[8,9]$.

Kenampakan tersebut ditandai dengan hasil yang merata dan tahan terhadap uji yang telah dilakukan. Data yang dihasilkan uji tersebut, diolah berdasarkan ANOVA dua arah dengan perbandingan antara perbedaan perlakuan komposisi terhadap jenis kain. Hasil dari olahan skala pada Tabel 1, Tabel 2, dan Tabel 3. Diubah ke dalam data skala interval ANOVA dihasilkan analisis perbandingan penilaian responden perbedaan jenis kain terhadap pengaplikasian komposisi pelarut merang bakar dinilai hampir seragam. Sementara penilaian responden pada beda komposisi terhadap penggunaan jenis fiksator menunjukkan potensi perbedaan yang nyata (Tabel 4, Tabel 5 dan Tabel 6).

Tabel 4. Analisa ANOVA (Between-Subjects Factors)

\begin{tabular}{|c|c|c|c|}
\hline & & Value Label & $\mathrm{N}$ \\
\hline \multirow{2}{*}{ Konsentrasi } & 1 & $\begin{array}{c}\text { Komposisi } \\
100 \mathrm{gr} / \mathrm{l}\end{array}$ & 36 \\
\hline & 2 & $\begin{array}{c}\text { Komposisi } \\
200 \mathrm{gr} / 1\end{array}$ & 36 \\
\hline \multirow{3}{*}{ Jenis kain } & 1 & Kain A & 24 \\
\hline & 2 & Kain B & 24 \\
\hline & 3 & Kain C & 24 \\
\hline
\end{tabular}

Tabel 5. Levene's Test of Equality of Error Variances ${ }^{a}$

\begin{tabular}{lccc}
\hline \multicolumn{4}{l}{ Dependent } \\
\hline $\mathrm{F}$ & $\mathrm{df} 1$ & $\mathrm{df} 2$ & Sig. \\
3.066 & 5 & 66 & .015 \\
Tests the & null hypothesis that the error variance of the \\
dependent variable & is & equal across & groups. \\
a. Design: & Intercept + Konsentrasi $+\mathrm{JK}+$ Konsentrasi \\
* JK
\end{tabular}


Tabel 6. Tests of Between-Subjects Effects

Dependent Variable: Persepsi

\begin{tabular}{cccccc}
\hline Source & $\begin{array}{c}\text { Type III Sum } \\
\text { of Squares }\end{array}$ & Df & $\begin{array}{c}\text { Mean } \\
\text { Square }\end{array}$ & F & Sig. \\
\hline $\begin{array}{c}\text { Corrected } \\
\text { Model }\end{array}$ & $41.949^{\mathrm{a}}$ & 5 & 8.390 & 11.836 & .000 \\
Intercept & 910.862 & 1 & 910.862 & 1285.00 & .000 \\
Konsentrasi & 36.937 & 1 & 36.937 & 52.109 & .000 \\
JK & 3.205 & 2 & 1.603 & 2.261 & .112 \\
Konsentrasi $*$ & 1.807 & 2 & .903 & 1.274 & .286 \\
$\quad$ JK & 46.783 & 66 & .709 & & \\
Error & 999.594 & 72 & & & \\
Total & 88.732 & 71 & & & \\
Corrected & Total & Adjusted $R$ Squared $=.433)$ & & \\
a. $R$ Squared $=.473$ (Ad)
\end{tabular}

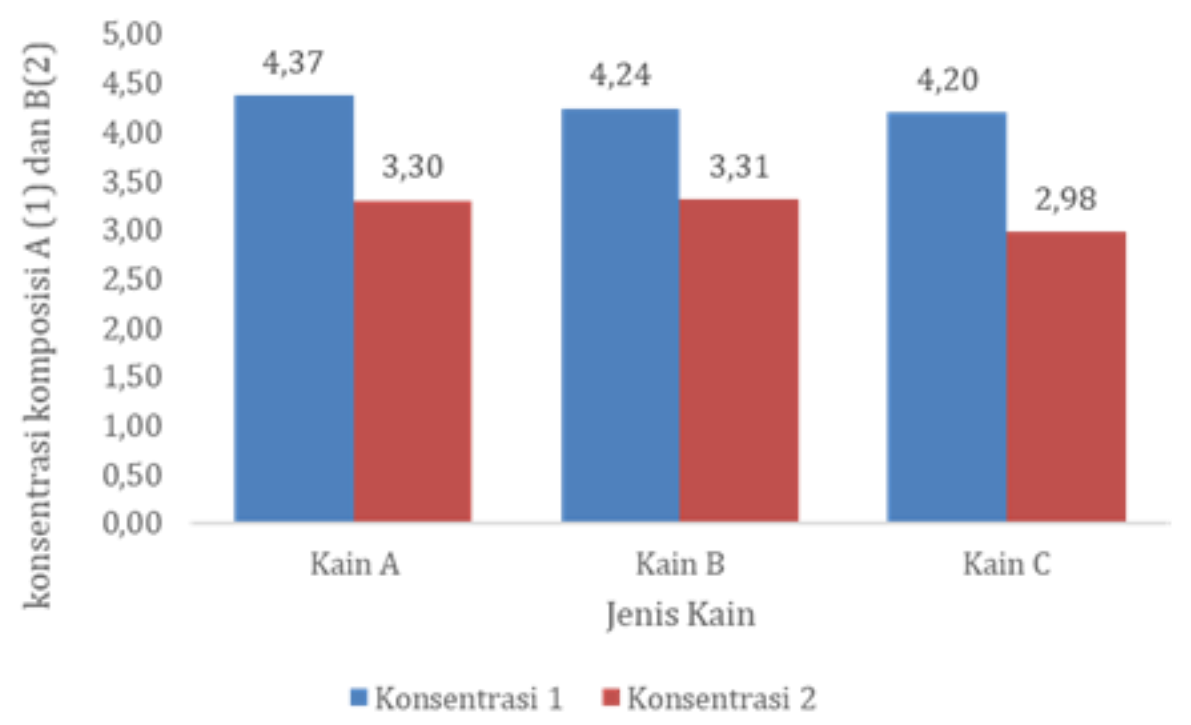

Gambar 1. Hubungan penilaian ragam nilai slaka fiksator terhadap perbedaan komposisi dan jenis kain

Gambar 1. memperlihatkam kondisi terbaik dari perbedaan perlakuan komposisi pelarut terhadap kain. Tetapi jika dilihat dari sudut pandang kain, tidak tampak berbeda. Komposisi terbaik pada perlakuan A (100gr/L) lebih baik jika dibandingkan komposisi B (200gr/L) hal ini dimungkinkan karena semakin besar penambahan pelarut pada pembentukan zat warna dengan serbuk bakau, maka keberadaan bakau menjadi lemah. Sehingga dominasi yang dihasilkan lebih kepada pelarutnya. Dimana pelarut abu merang sendiri ditambahkan dengan tujuan memperjelas warna bakau. Tetapi jika kadar pelarutnya lebih besar, maka yang terjadi adalah dominasi pelarut yang kemungkinan tidak menyatu dengan bahan baku (serbuk bakau). 
Dominasi pelarut tersebut, ketika diaplikasikan pada jenis kain, kurang memiliki daya serapan pada selulosa kain. Sehingga ketika diuji pada pencucian, kelunturan dan dijemur pada terik matahari akan lebih cepat memudar, meski diberikan fiksaator. Hal ini sependapat dengan penelitian yang dilakukan di dalam [3], dan penelitian yang dilakukan di dalam [4] bahwa semakin besar massa bahan pada perrbandingan pelarut maka hasil \%yield yang diperoleh cenderung turun. Hal ini dikarenakan semakin besar rasio bahan terhadap pelarut menyebabkan luas bidang kontak antara bahan terhadap pelarut semakin kecil, sehingga kemampuan pelarut untuk mengekstrak zat warna ikut berkurang dan mengakibatkan zat warna tidak terekstrak semua.

\section{KESIMPULAN}

Kesimpulan Dari hasil penelitian ini dapat disimpulkan bahwa perbedaan jenis pelarut dengan komposisi A 100gr/l lebih baik dibandingkan dengan komposisi B $200 \mathrm{gr} / \mathrm{l}$ untuk ragam persepsi kain dan jenis fiksator. Sedangkan pada perbandingan ragam persepsi terhadap kain tidak ditemukan perbedaan yang nyata.

\section{DAFTAR PUSTAKA}

[1] N. W. Halizah, "Pengembangan Propagul Kering Tanaman Bakau (RhizophoraSpp.) Sebagai Pewarna Alam Dengan Teknik Celup Rintang," Universitas Telkom, Bandung, 2017.

[2] D. Ramadhania, "Pengaruh Perbedaan Cara Ekstraksi dan Bahan Fiksasi Bahan Pewarna Alam Limbah Serbuk Kayu Mahoni (Swietenia macrophylla King) Terhadap Kualitas Pewarna Batik," Universitas Gajah Mada, Yogyakarta, 2010.

[3] M. D. Cahyani and I. N., "Ekstraksi Zat Warna Alami Dari Kayu Bakau (Rhizophora Mucronata) Dengan Metode Microwave Assisted Extraction," Institut Teknologi Sepuluh Nopember, Surabaya, 2016.

[4] Warnoto, "Kajian Zat Warna Alami (ZPA) Dari Ekstrak Kulit Kayu Bakau(rhizopora Sp.) Sebagai Pewarna Kain Ramah Lingkungan," Universitas Islam Negeri Sunan Kalijaga Yogyakarta, Yogyakarta, 2015.

[5] A. Triani, C. T.J., J. N. and K. Bayu, "Pencarian Hasil Pencelupan Optimum dari Ekstrak Biji Buah Tanaman Kesumba pada Kain Kapas, Sutera, Poliamida, dengan Variasi Penambahan Zat Pembantu dan Proses Fiksasi.," 5 August 2012. [Online]. Available: https://potretnugraha.wordpress.com.

[6] T. Pujilestari, "Pengaruh Ekstraksi Zat Warna Alam dan Fiksasi Terhadap Ketahanan Luntur Warna Pada Kain Batik katun," Dinamika Kerajinan Dan Batik, vol. 31, no. 1, pp. 31-40, 2014.

[7] P. Mayangsari, M. Febiantika, F. DANOVAn, F. Nurani and W. Permatasari, "Review: Usaha Untuk Menjaga Ketuaan Warna Hasil Pencelupan Kain Denim Dengan Zat Warna Indigo Dengan Mengatur pH Larutan Celup," STT Tekstil, Bandung, 2012.

[8] R. E. Prayitno, S. Wijana and D. Diyah, "Pengaruh Bahan Fiksasi Terhadap Ketahanan Luntur dan Intensitas Warna Kain Mori Batik Hasil Pewarnaan Daun Alpukat (Persea americana Mill.)," Universitas Brawijaya, Malang, 2014. 